\begin{tabular}{|c|c|}
\hline \multirow{3}{*}{ 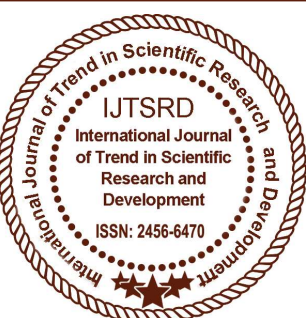 } & $\begin{array}{l}\text { International Journal of Trend in Scientific } \\
\text { Research and Development (IJTSRD) }\end{array}$ \\
\hline & International Open Access Journal \\
\hline & ISSN No: 2456 - 6470 | www.ijtsrd.com | Volume - 2 | Issue -3 \\
\hline
\end{tabular}

\title{
Android based Digital Attendance System using GSM
}

\author{
${ }^{1}$ Ritesh D. Survase, ${ }^{1}$ Sharad S. Soma, ${ }^{1}$ Girish H. Watte, ${ }^{2}$ Mr. Jatin M. Patil \\ ${ }^{1}$ UG Student, ${ }^{2}$ Assistant Professor \\ ${ }^{1,2}$ Department of Electronics \& Telecommunication Engineering, \\ Brahmdevdada Mane Institute of Technology, Solapur, Maharastra, India
}

\begin{abstract}
Attendance recording in educational institutions is an important task. But now a day's manual data entry procedures are used to take the attendance. Traditional ways of recording attendance involve manual entering of individual attendance on a sheet of paper. Later, these are fed into staff diary or computer database.
\end{abstract}

In this system we are focusing on developing this project, which will help the lecturers to take attendance easily, securely and will have less error. For this we are implementing android based software for digital attendance system at teacher's Android mobile phone and student's Android mobile phone.

This system will helps lecturers to take attendance of the students using android mobile phone, by using mobile application those who are present in the class, whose attendance will be marked. After that captured data will be sent to server database from where attendance list will be updated automatically on the server's data base, lectures will able to edit the attendance and easily get requested information. This system helps teacher to take attendance through Smartphone and keep record of students for their progressive assessment. This system gives a prior intimation to student as soon as their attendance goes below the specified attendance threshold in the form of an SMS

Keywords: Attendance system, GSM Modem, Web server, Android Technology, Mobile Phone, Visual Basic

\section{INTRODUCTION}

Now days, mobile devices have become a way of life for students especially in higher education. Computers are now replaced by compact smart phones that can be fit into pocket and can be carried anywhere. The rapidly with development of this Android application the student preferred to use mobile devices as technology supported educational tool.

This system is designed because notes dictation in the class is difficult considering semester duration, student might miss the exam and important notice displayed due to unawareness, chances of false marking of attendance is more due to more paper work and manual attendance entry, evaluation and report generation is tedious and time consuming job.pid progress in mobile technology has created a new area which is known as mobile learning.

Our project aims in implementing software that will help lecturers to take the attendance of students using android based mobile phone. After taking the attendance in the mobile phone, lecturer will update attendance of students in the web server. Keeping in view the importance of attendance recording, our proposed system provides fast solution for any organization especially academic institutions

An Education system in India has become so advanced in last decade due to the development of the technology. Smart class, video conferencing are some of the examples of modern trends in educational system. These applications help the institute to move forward quickly, fulfill their vision and accomplish their goals, E-way. The core idea of research project is to implement Android based application for 
attendance management system for advancement of institution and educational system.

\section{HARDWARE USED}

The hardware tools used include GSM modem, RS 232, PC. The software tools are used include JAVA, VB, Android studio.

\section{GSM}

This GSM Modem can accept any GSM network operator SIM card and act just like a mobile phone with its own unique phone number. Advantage of using this modem will be that you can use its RS232 port to communicate and develop embedded applications. Applications like SMS Control, data transfer, remote control and logging can be developed easily

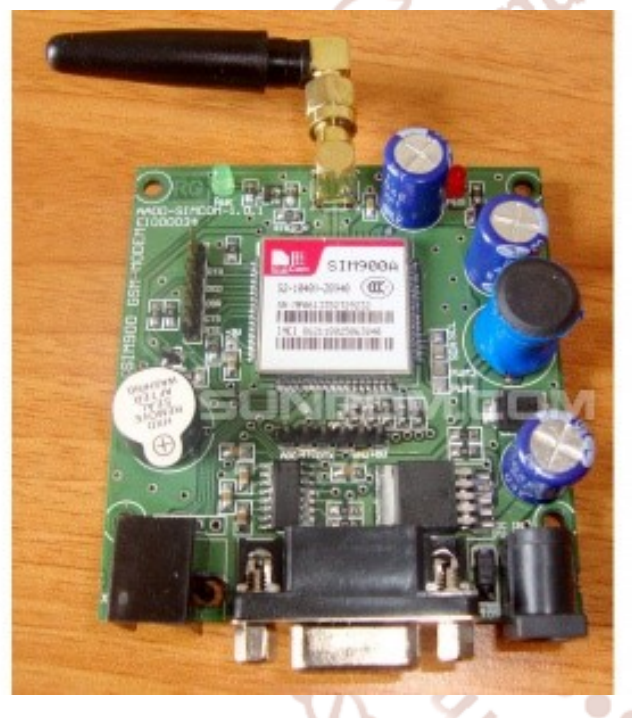

Fig 1) GSM SIM 300 MODEM

The modem can either be connected to PC serial port directly or to any microcontroller through MAX232. It can be used to send and receive SMS or make/receive voice calls. It can also be used in GPRS mode to connect to internet and do many applications for data logging and control. In GPRS mode you can also connect to any remote FTP server and upload files for data logging. This GSM modem is a highly flexible plug and play quad band SIM300A GSM modem for direct and easy integration to RS232 applications. Supports features like Voice, SMS, Data/Fax, GPRS and integrated TCP/IP stack.

\section{RS232 serial interface cable}

In telecommunications RS 232 recommended standard 232 for serial communication transmission of data. it formally defines the signals connecting between a DTE such as a computer terminal and a DCE such as a modem

\section{SOFTWARE TOOLS}

\section{1) Android Studio}

Android studio's job is to provide the interface file management for you create your apps and to handle much of the complicated file management behind the scene. The programming language you will be using is java and this will be installed separately on your machine. Android studio is simply where you will write, edit and save your projects and the files that comprise said projects. At the same time, Android studio will give you access to the Android SDK or 'Software development kit' think of this as an extension to the java code that allows it to run smoothly on Android devices and take advantage of the native hardware. Java is needed to write the programs run on Android studio has putting it all together for you. Those programs run, at the same time, Android studio also you to run your code, either through a piece of hardware connected to machine.

\section{2) Visual Basic}

The "Visual" part refers to the method used to create the graphical user interface (GUI). Rather than writing numerous lines of code to describe the appearance and location of interface elements, you simply add prebuilt objects into place on screen. If you've ever used a drawing program such as Paint, you already have most of the skills necessary to create an effective user interface.

The "Basic" part refers to the BASIC (Beginners AllPurpose Symbolic Instruction Code) Visual Basic has evolved from the original BASIC language and now contains several hundred statements, functions, and keywords, many of which relate directly to the Windows GUI. Beginners can create useful applications by learning just a few of the keywords, yet the power of the language allows professionals to accomplish anything that can be accomplished using any other Windows programming language

Data access features allow you to create databases, front-end applications, and scalable server-side components for most popular database formats, including Microsoft SQL Server and other enterpriselevel databases. 


\section{METHODOLOGY}

This project is developed by using Android Studio, visual basic language. It is divided into two phases. In the very first phase, feasibility study is conducted; requirement analysis is carried out to understand the need for the system and the necessary modules, such as student module, teacher module, and parent's modules. In the web based module is for the admin panel to control its all over activates like updating, creation, deletion or any other database changes in the whole project by the teacher. On the other hand the mobile based application will be totally used by the teacher to get logged in and by choosing their authorized register class id and the subject id they are able to display the digital register book on their smart mobiles onwards and submit it finally by cross checking it to the main authorized provide teacher server through GSM.

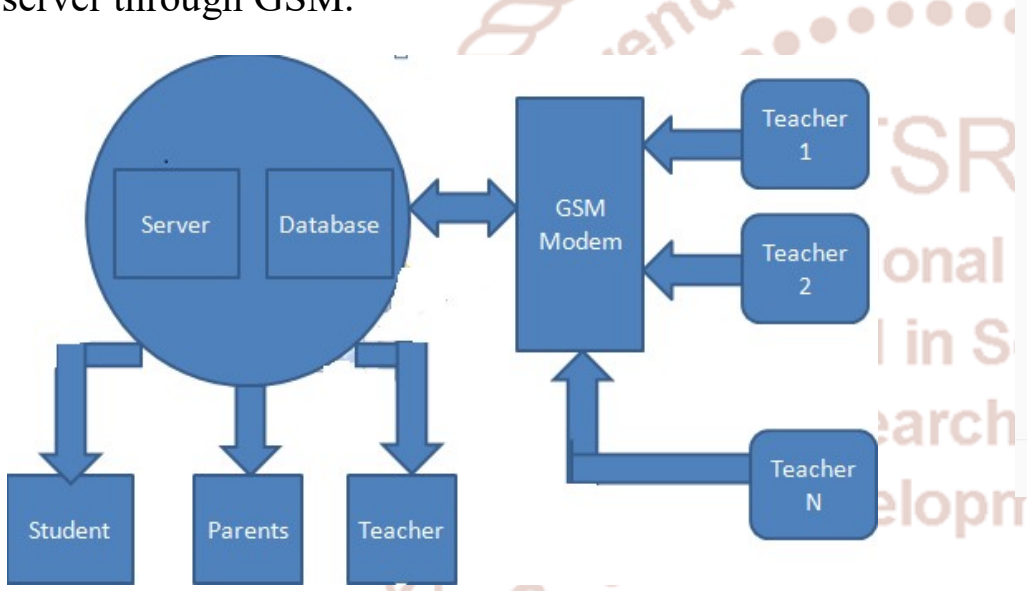

Fig 2) Block diagram of Android based digital attendance system using GSM

\section{Advantages}

- Reduce paper work and save time and money.

- Keep the parents informed about the student's attendance via SMS alerts.

\section{Future scope}

As soon as the students log in the application in the class, they will be available for the attendance. The lecturer will then submit the attendance using the availability of the students those who are logged in.

SMS module can be implemented which will inform students about low attendance and various events.

\section{APPLICATION}

It can be used wherever the attendance is a necessity such as Schools, Colleges and Institutes and almost everywhere.

\section{RESULT}

This implementation is done on the server and Smartphone. Implementation on the server is done using visual basic, while the implementation of Smartphone is using java. The application is tested on Android Smartphone.
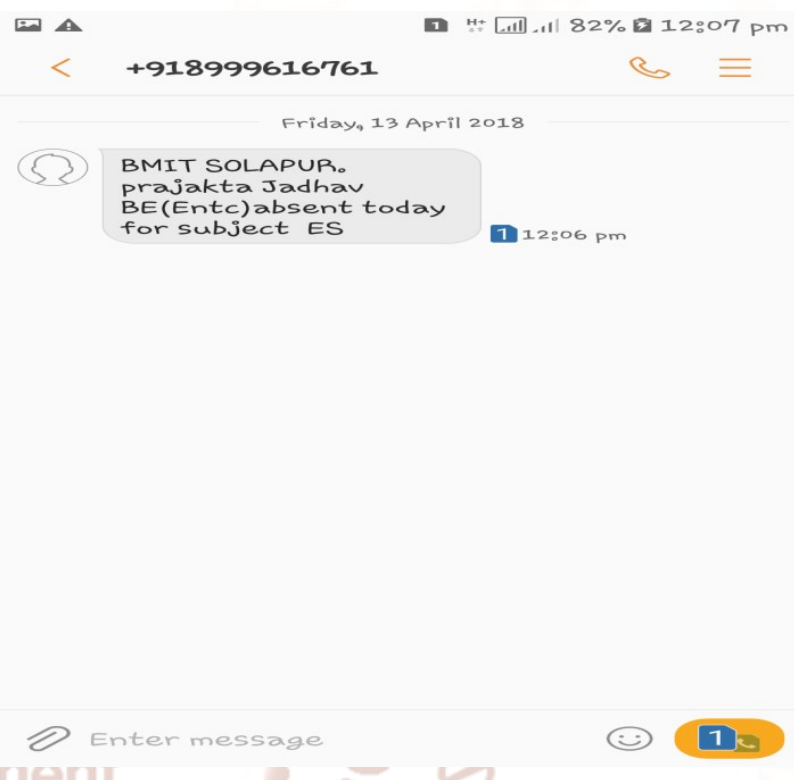

Fig 3 SMS snapshot of HOD

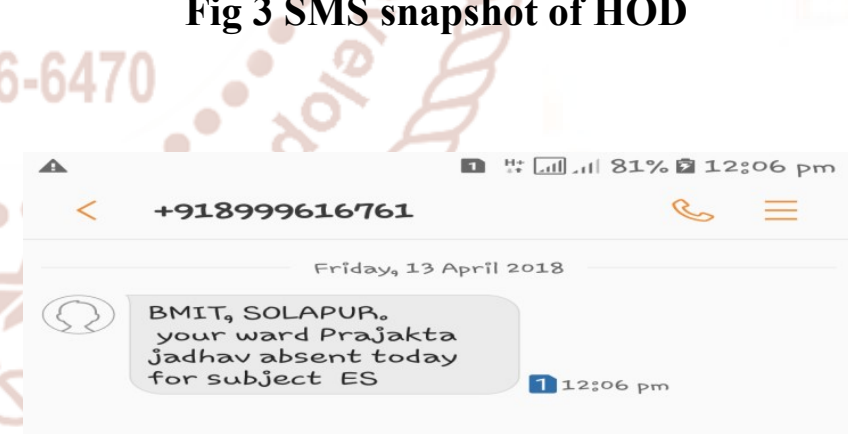

MIT, SOLAPUR. tour wardprajakt for subject ES

1. $12: 06 \mathrm{pm}$ 


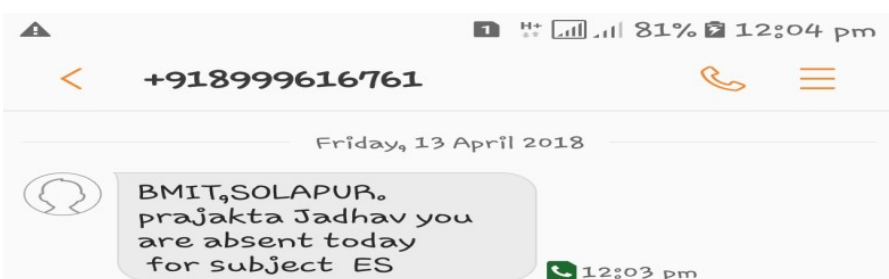

$Q$ Enter message

Fig 5) SMS snapshot of Parents

\section{CONCLUSION}

The developing idea as an Android based attendance system using GSM is on the verge of introducing worldwide institutions into an automated way of recording student's attendance. It will, by far, improve the current manual process of recording student's attendance. This system promotes a way for students to 'sign' there attendance on a digital form and in contactless mode.

\section{REFERENCES}

1) Dhiman Kumar Sarker, NafizeIshtiaqueHossain, Insan Arafat Jamil, "Design and implementation of smart attendance management system using multiple step authentication", Computational Intelligence (IWCI) International Workshop on, pp. 91-95, 2016.

2) Ononiwu G. C and Okorafor G. N (2012): Radio

Frequency Identification (RFID) Based Attendance System With Automatic Door Unit, Academic Research International. Vol 2, No 2, March, 2012.

3) Vishal Bhalla, Tapodhan Singla, Ankit Gahlot and Vijay Gupta, "Bluetooth Based Attendance Management System", International Journal of Innovations in Engineering and Technology (IJIET) Vol.3 Issue 1 October 2013, ISSN: 2319 1058.

4) Conference paper- June 2015-A review of student attendance system using near - field communication technology.

5) Monika singh, Divya Tripathi, Ashutosh Pandey, Rakesh Kumar singh -mobile based student attendance management system 